\title{
INVESTIGATING TRANSPORT INFRASTRUCTURE OBJECTS WITHIN THEIR SPATIAL DEVELOPMENT LIFECYCLE
}

\author{
E. Kalogianni*1 ${ }^{*}$, G.S. Floros ${ }^{2}$, E. Dimopoulou ${ }^{3}$ \\ ${ }^{1}$ Architectural Engineering and Technology Department, Delft University of Technology - E.Kalogianni@tudelft.nl \\ ${ }^{2}$ Skanska UK-Infrastructure - Georgios.Floros@skanska.co.uk \\ ${ }^{3}$ School of Rural and Surveying Engineering, National Technical University of Athens, Greece - efi@ survey.ntua.gr
}

KEY WORDS: LADM, ISO19152, Infrastructure assets, Transport infrastructure assets, BIM, IFC, Spatial Development Lifecycle

\begin{abstract}
:
Precise and detailed information for infrastructure assets, as well as information about the property interests attached to them are crucial to prevent unnecessary costs, disruptions, and delays when planning, constructing, and managing such objects. Various models encapsulating infrastructure objects information are available, mostly during their design stage, and could be also reused in other stages of the Spatial Development Lifecycle (SDL), such as the Land Registration. In this respect, and as ISO 19152:2012 Land Administration Domain Model is currently under revision, it is well-timed to consider the modelling of infrastructure objects within the scope of the upcoming Edition II of the standard. Given this background, the aim of this paper is to initiate the discussion on the registration options of infrastructure objects in the context of the LADM revision. Attention is given on specific categories of transport infrastructure objects, identifying the information required to be reused in other stages of the SDL, sourced from BIM/ IFC files used in the design stage. As currently IFC does not support infrastructure information, in order to investigate how such information is stored in IFC models based on the modellers' decisions and the software used, two models of transport infrastructure objects coming from the industry were inspected and based on these findings, the conceptual modelling followed, based on the LADM concept. The paper aims to provide insights on to the limitations of the current use of IFC for transport infrastructure objects and propose the future steps to overcome them.
\end{abstract}

\section{INTRODUCTION}

Detailed and comprehensive knowledge about 3D urban space, critical infrastructures, and below ground assets is a prerequisite for management, simulation, and analysis in the fields of urban and environmental planning and governance, land administration and disaster management. Accurate information for those assets is the most valuable commodity to have for the management and protection of infrastructure assets, as well as a clear and accurate definition of ownership rights restrictions and responsibilities associated with them. A reliable and complete registration and representation of legal spaces can prevent unnecessary costs, delays and disruptions in many projects (Rajabifard et al., 2019) and this applies even more to large scale infrastructure projects.

As stated by Strange (2018), the role of infrastructure in the built environment regarding the development and efficient function of a sustainable, resident city, continuously increases as it is interrelated with its social, environmental, and economic performance. The AECOO (Architecture, Engineering, Construction, Owner, Operation) industry, is considered directly responsible for addressing this challenge, and in this regard, the (combined) use of BIM and GIS is investigated (Floros, et al., 2020). In this context, standards in both domains play a crucial role providing interoperability options for data storage and exchange across the various phases of an object's lifecycle. There are various standardised approaches and formats that are being used in the AECOO industry, which vary and depend on multiple factors (custom-made methodologies, stakeholders' expertise, project budget and timeline, etc.), while it also happens that no standardised models are being used or are adjusted according to the project's needs and requirements.

Some of the dominant standards used in the infrastructure sector are presented in Section 2.3. In the context of this paper, attention is given to the Industry Foundation Class (IFC) standard, as the most common data storage and exchange format for Building Information Models/ Modelling (BIM), which is gaining momentum in the AECOO industry, being adopted, and massively used worldwide for infrastructure projects and mainly for buildings. In this scene, there has been significant research on the intersection of 3D land administration and BIM over the recent years. This is because, a BIM-based solution for 3D Land Administration Systems (LAS) provides a rich repository for legal and physical datasets in a common environment, while the knowledge encapsulated inside a 'cadastral BIM model' should be tapped to unlock the value of 3D cadastral information (Atazadeh et al., 2019). Although BIM models can provide a solid base of information for objects' registration, there are too main issues encountered: firstly, the fact that this information can be too detailed, and thus, a simplification is needed to identify the required -for land administration (LA) applications- insights; while information related to ownership status and transaction record is not stored in such model (Liu et al., 2017).

Given this background, this paper investigates and categorizes infrastructure objects and their requirements within the context of reusing information through the Spatial Development Lifecycle (SDL) stages. In this regard, an approach to collect, reuse, exchange, and share 3D data, through the SDL, could improve the efficiency of current situation (in terms of time and cost), while data will become suitable for various applications (Kalogianni et al, 2020). The role of LA in the Spatial Development Lifecycle (SDL) is mainly associated with the registration, however it also affects each one of the other phases, as presented in Section 2.2.

Standardization plays a key role in the SDL context, as it aims to ensure the ability to integrate heterogenous datasets from various sources, while reducing costs and dependence on implementation 
specifics (software, etc.). The need to register infrastructure objects in 3D LAS with a standardised way arises from a plethora of reasons, namely: the nature/physical aspect of such objects as they are usually complex structures need to be described in $3 \mathrm{D}$; their legal interests (Rights, Restrictions and Responsibilities) that go beyond traditional 2D cadastral systems; the importance of their location for risk management or strategic reasons (i.e. in case of cross-border infrastructure objects) that requires a standardised and harmonised way to manage them, as well as their economic value that asks for an efficient asset management through all phases of their SDL.

Nonetheless and as the Land Administration Domain Model (LADM, ISO 19152:2012) is currently under revision; it will be wise to consider the modelling of such objects within the scope of the upcoming Edition II of the standard. This second edition will be multipart, with a wider scope and refinements on the Edition I. Further information about the LADM Edition II is given in Section 2.4.

Given this background, this paper aims to initiate the discussion on the registration of some categories of infrastructure objects in the context of LADM revision. Since there has been limited research being carried out in this domain, the paper commences with a categorisation of infrastructure objects according to the literature, presenting dominant standards being used by the industry during design and construction and proposes a conceptual modelling approach aligned with the LADM revision.To articulate the requirements of infrastructure objects' data reuse and validate this approach, two real world BIM/ IFC data from large-scale infrastructure objects are inspected against selected criteria. Finally, the paper concludes with discussion on the findings and future work proposals.

\section{RELATED WORK}

\subsection{Infrastructure objects: definition and categorisation}

Infrastructure is defined by the oxford dictionary (Oxford University Press, 2016) as "the basic physical and organizational structures and facilities needed for the operation of a society or enterprise". Therefore, infrastructure assets can be categorised into five main domains (Cheng et al., 2016):

- Transportation infrastructure - roads, railways, bridges, tunnels and mass transit hubs (airports, ports \& harbours);

- Energy infrastructure - power generation plants (nuclear, wind, tidal etc.), oil \& gas (storage/distribution terminals, refineries, wells etc.) and mining;

- Utility infrastructure - electricity, gas, water \& sewage networks/pipelines;

- Recreational facilities infrastructure - Parks, stadiums etc.;

- Environmental infrastructure - Structures for managing flood and coastal defence such as dams, levees, weirs, or embankments.

Apart from this thematic categorisation, those assets differentiate also in terms of geometry and semantic characteristics, on their relation to the ground (above, below, mixed) and the legal interests attached on them (RRRs). In the context of this paper, objects lying on the first category "Transport infrastructure" are being investigated and analysed and specifically, bridges and tunnels.

\subsection{Spatial Development Lifecycle (SDL)}

The key industry sectors directly associated with the interdisciplinary aspects of design, construction, operation and maintenance of the created surroundings and artefacts, are: the AECO (Architecture, Engineering, Construction and Operation), Land Administration, and Urban Planning industries. Although interwoven in certain aspects, these domains rely on different systems in the collection, storage, management, and dissemination of built environment-related information (Kalogianni et al., 2020). In practice, those disciplines are mutually affected, and this does not only apply to the objects of the built environment that already exist, but also to those that are in the design process.

Progress in the use of integrated datasets from heterogenous sources has proven to be time and cost consuming. In this scene, collaboration according to guidelines and specifications across the involved stakeholders of the SDL phases (see Figure 1) is expected to facilitate data harmonisation and data use (Kalogianni et al., 2020). Additionally, design and data acquisition efficiency are expected to be improved; while data quality (against specific regulations) to be enhanced; mismatches, data loss and overlaps between the various stages to be reduced, aiming to increase reuse of data from design phase to registration/operation.

Resolving issues on data sharing and data integration will increase effectiveness in the SDL by the provision of an efficient, well-organised data flow based on standards and to achieve it, it is necessary to formalise the requirements of the different types of infrastructure objects.

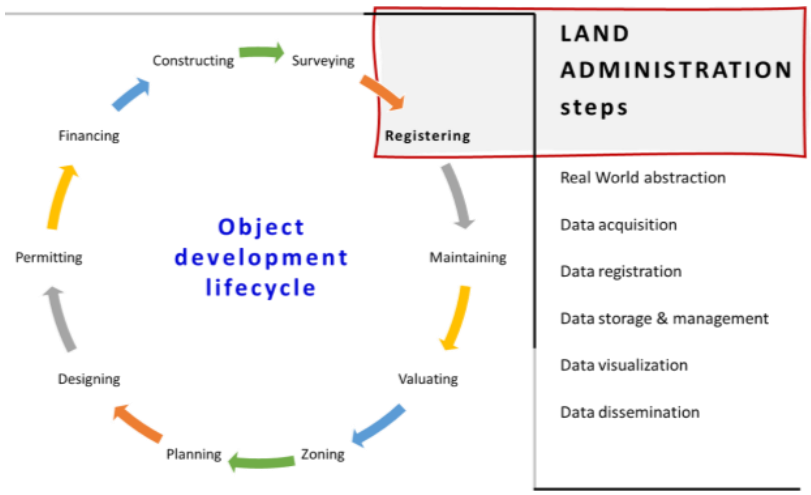

Figure 1. Phases of the Spatial Development Lifecycle (Kalogianni et al., 2020)

The importance of using standards and digital technologies in SDL is also underlined in different global documents, such as the recent Report of the European Construction Sector Observatory (EC, 2021). As presented in Fig. 2, BIM covers the whole spectrum of design, construction, operation and maintenance and renovation, as well as during the rest of SDL phases; surveying, registering, valuating, planning, zoning and permitting. 


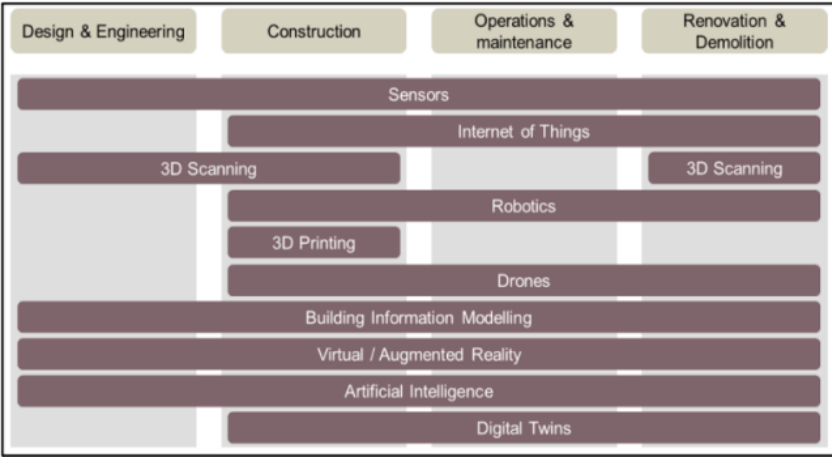

Figure 2. The use of digital technologies in various SDL phases (EC, 2021)

\subsection{Standards enhancing interoperability in the infrastructure sector}

The most dominant standards used for storage and exchange of infrastructure geometry and the related semantic information are briefly introduced in this subsection.

2.3.1 Uniclass2015 is a classification system of the built environment for the AECOO industry, emphasising on lifecycle information management (Gelder, 2015) and is organised in levels, varying from the description of the generic asset class (e.g. highways, bridge) up to specific asset elements e.g. (beams, handrail) (NBS, 2021). Uniclass2015 is introduced typically during the design stage and is used for multiple purposes including estimating, CAD drawing and layer specification (Floros, 2020).

2.3.2 LandInfra (Land and Infrastructure) is an open standard from the OGC (Open Geospatial Consortium), focusing on land and civil engineering infrastructure facilities, including roads, buildings, railways, projects, alignments, surveys, land features and land divisions (OGC, 2016) and interests in land. 'Wet' infrastructure is slated for a future version, including features such as storm drainage, wastewater, and water distribution systems (Kumar et al., 2019). LandInfra is introduced as the proposed successor to LandXML.

2.3.3 CityGML is an OGC standard for modelling, storing, and exchanging semantic 3D city models. The data model of CityGML comprises a core module and several thematic modules, that are being revised and enriched in the upcoming version 3 of the standard. Among others, there are thematic classes for Bridge, Tunnel, Transportation, ReliefFeature (LandSurface) and Construction (Kutzner et la., 2020). Moreover, Application Domain Extensions (ADE) have been developed or are being proposed as built-in mechanisms of CityGML to augment its data model with additional infrastructure concepts, such as the Utility Network ADE, the Transport ADE and the Infra ADE (Kumar et al., 2019).

2.3.4 INSPIRE was initially created to facilitate the standardisation and organisation of spatial information about the environment in Europe (INSPIRE, 2009). Among INSPIRE Themes, the INSPIRE transport networks includes spatial, temporal, and thematic elements for road, rail, air and water transport networks and related infrastructures.
2.3.5 IFC is an open data model and the most commonly used information exchange format specification for BIM models (buildingSMART, 2021), initially focusing on modelling features during the construction stage of the technical lifecycle. IFC is an object-oriented data model distinguishing its entities based on whether they represent objects, semantic information, or relationships (Floros et al. 2019; Theiler, 2018). IFC currently supports the "Building" city object, with the coverage for Infrastructure objects being under research, focusing on Roads, Tunnels and Bridges among others (buildingSMART Infrastructure Room, 2021).

As BIM-based models are complex and provide a range of information, there is an increasing standardisation activity in this domain, to provide standardised guidelines. BS EN ISO 19650:1 and BS EN ISO 19650:2 are the latest Standards on Information Management formulating the strategy and the BIM process that is outlined within the BIM Execution Plan (Çekin, 2020).

The ISO 19650 series are aligned with the British set of Standards PAS 1192; however they provide an international outreach (TheNBS, 2021).

There are also European approaches and guidelines on BIM adoption, such as the Common BIM Requirements (known as COBIM) in Finland (BuildingSmart, 2012), Norway's Statsbygg BIM Manual (Statsbygg, 2020) and Netherlands Rgd BIM Standard (Rijksgebouwendients, 2013). What is more, UK is one of the one of the global leaders in BIM, since there is the UK BIM Strategy, which mandates a certain level of BIM implementation on public projects by 2016 , the UK BIM Framework, which sets out the approach for implementing BIM using the framework for managing information provided by the EN ISO 19650-1:2018 series and the BIM Protocol, a standardised supplementary legal agreement that can be incorporated into professional service appointments and construction contracts by a simple amendment. Moreover, Singapore, Korea, the USA, and Australia form the rest of the international "avant-garde" in BIM policy making. In all these countries, the government and its subsidiary authorities have played a key role in demanding and fostering the adoption of BIM, however, by implementing significantly diverging approaches (Ghang et al., 2020).

2.3.6 The MUDDI (Model for Underground Data Definition and Integration) is a conceptual model, a modular framework, one or more logical models, one or more implementation specifications, and mappings to/from other models for geospatial data that represent underground infrastructure assets and characterize the underground environment that contains those assets (OGC, 2019). The MUDDI approach emphasizes the definition of common concepts and terminology that mediate between elements in existing relevant data models and can be used to integrate underground data from disparate sources leveraging those models.

\subsection{The ISO 19152:212 LADM revision}

The ISO19152 Land Administration Domain Model (LADM) is currently under revision and a new edition of the standard is under further development in ISO/TC 211 on Geographic Information. The Committee is developing this new edition of the LADM - as multipart - with the following working titles (Lemmen et al., 2021):

Part 1 - Fundamentals of Land Administration

Part 2 - Land Registration

Part 3 - Marine Space Georegulation

Part 4 - Valuation Information

Part 5 - Spatial Plan Information

Part 6 - Implementations 
The Part 1 will be a high-level umbrella standard that supports all the other parts of the LADM Edition II. Part 1 will present the fundamental notions and define the basic components and relations shared by all objects created by land administration, as well as provide an overview of all parts. The Part 1 will not only be backward compatible with the previous version of LADM but also with the IHO S-121 Maritime Limits and Boundaries standard (IHO, 2016), which will be used as basis when developing the Part 3 of LADM Edition II (Lemmen et al., 2021).

Part 2 is focused on Land Administration, Land Registration and Cadastre, while some of the existing parts of LADM Edition I are being refined in Part 2 aiming to add more semantics to the LADM. Representative examples of such improvements are the Survey Model and the semantically enriched, structured and versioned code lists. What is more, in order to support a variety of spatial unit types, a need that was also identified through the country profile developments, the Edition II - Part 2 will include 4 subclasses of LA_SpatialUnit class: LA_LegalSpaceUtilityNetwork (was already included in Edition I), LA_LegalSpaceBuildingUnit (was already included in Edition I), LA_Parcel and LA_LegalSpaceInfrastructure.

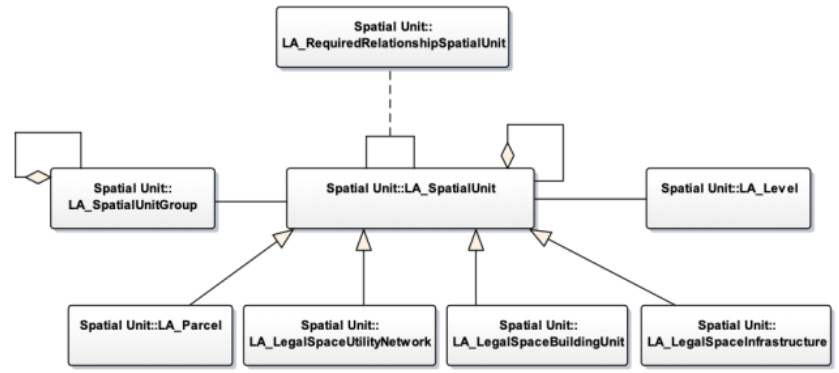

Figure 3. Classes of Spatial Unit Package of LADM Edition II Part 2 Land Registration (Lemmet et al., 2021)

The four specializations of the 'LA_SpatialUnit' class in LADM II - Part 2 present different (thematic and geometrical) characteristics with regards to each other and/ or relationships, and thus they are modelled separately. They refer to the following spatial unit types:

- land parcel of any use type: residential, agricultural, industrial, mixed, etc.

- utility network (gas, oil, heating, etc.) concerning legal space, which does not necessarily coincide with the corresponding physical space.

- building unit (shared or individual) concerning legal space, which does not necessarily coincide with the corresponding physical space.

- $\quad$ infrastructure object, concerning legal space, which does not necessarily coincide with the corresponding physical space.

In the context of this paper, attention is given on the modelling of infrastructure objects considering the above-mentioned spatial unit types of LADM Edition II and more specifically on tunnels and bridges.

\section{RESEARCH METHODOLOGY}

This paper aims to investigate the efficient reuse of BIM/ IFC files for land administration applications within the SDL. To achieve this, the research methodology followed, is presented in Figure 4. However, as there has been no significant previous research in this field, attention was given on the inspection of
BIM/ IFC files and the identification of patterns and requirements that will guide the conceptual modelling procedure. IFC files are being inspected automatically by using IFC validation tools (Solibri Model Checker, IFC File Analyzer) and manually through IFC viewers and populated database tables.

Two IFC files, further described in Section 4, have been collected and studied against some criteria. Specifically, for both files the following aspects have been investigated:

- $\quad$ georeferencing

- IFC modelling

- use of semantics/ attributes

- use of 'IfcBuildingElementProxy'

- geometry

Georeferencing on those IFC models is examined according to the criteria proposed by Clemen and Görne (2019). The IfcBuildingElementProxy is examined separately from other IFC elements, as it handles the occurrence of any building element and the common information about the types (or styles) and as there are no dedicated classes yet to store specific infrastructurerelated, part of the information is stored there.

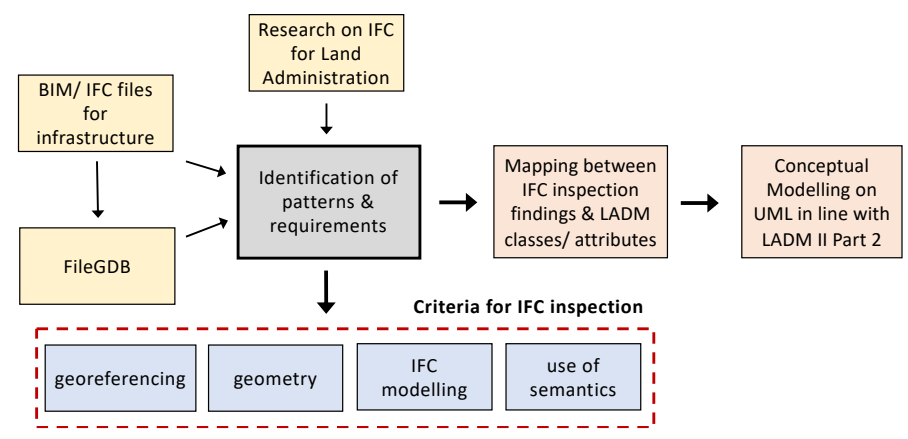

Figure 4. Research Methodology

Then, the findings from the IFC inspection led to their mapping with LADM classes and/ or attributes and accordingly to the development of the UML diagram to populate the 'LA_LegalSpaceInfrastructureObject' class of the Spatial Package of LADM II - Part 2. For the creation of UML models, Enterprise Architect is used.

\section{CASE STUDIES AND DATASETS}

The two models of infrastructure objects selected as case studies to observe and identify their characteristics that could be useful to be registered in LAS are: (i) a 3D model of a Bridge used in Highways Transportation and (ii) a 3D model of a Tunnel used in Rail Transportation. The selection of these two models is based on the frequency that these objects are part of a Highways or Rail network as well as the current state of art which focuses on extending IFC for these Infrastructure objects.

The 3D Models are provided by Skanska UK Plc (a global construction company operating in the UK) and the Joint Venture "Skanska - Costain - STRABAG" (working on behalf of HS2 in the UK) reflecting works with Highways England (a public body managing the strategic road network in England) and HighSpeed 2 (a new high-speed railway in the UK linking London, the Midlands, the North and Scotland).

The 3D Model of the bridge is produced using Autodesk Revit 2020 and exported to IFC 2 X3 reflecting the Scheme Design stage of the technical lifecycle. 


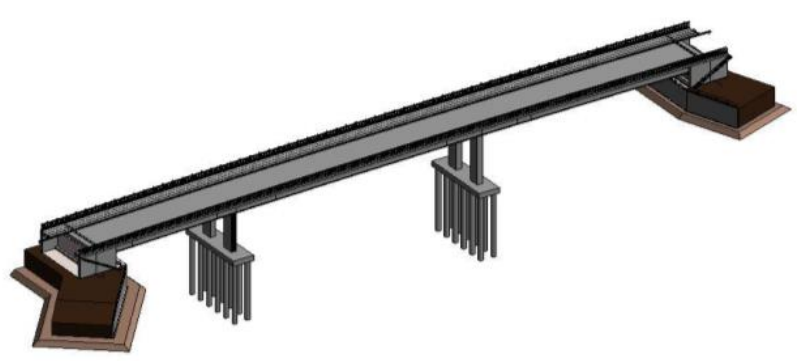

Figure 5. The 3D model of the bridge.

The 3D Model of the Tunnel is produced using Bentley AecoSIM and exported to IFC 2 X3 reflecting the Scheme Design stage of the technical lifecycle.

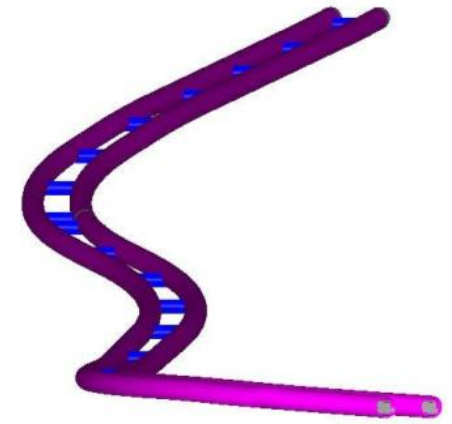

Figure 6. The 3D model of the tunnel.

The 3D Models are utilised in two different Infrastructure sectors: Highways and Rail, meaning that the 3D Modelling and Authoring tools vary and consequently the non-graphical information that is being captured within each is tailored to address the requirements of each project. There is a level of overlap with regards to capture information such as Uniclass 2015, Material, Asset Classes as well as geometric characteristics such as Volume, Height and Length.

Two different 3D Modelling and Authoring tools are used to produce the models: Autodesk Revit and Bentley AecoSIM. The conversion of the IFC Models to 3DGIS is performed using an Extract-Transform-Load (ETL) software tool and in particular Feature Manipulation Engine (FME) with the visualisation of the 3DGIS output taking place in Esri ArcGIS Pro.

\section{IFC INVESTIGATION RESULTS AND CONCEPTUAL MODELLING OF INFRASTRUCTURE OBJECTS IN THE CONTEXT OF LADM EDITION II}

The aspects listed in Section 3, where used as criteria to inspect the two IFC files. Based on those findings (Table 1), the mapping with core LADM concepts is performed, followed by the creation of the LADM-compliant UML model, presented in this section.

Both files are IFC 2X3 schema. Georeferencing IFC files could become a complicated process. However, as stated by Clemen and Görne (2019), there is a number of options to store information about georeferencing in IFC, ranging from basic/ simple address information to more complex, such as the definition of coordinates according to a projected Coordinate Reference System (CRS). What is more, the "correct" use of semantics (with regards to the use of appropriate IFC elements) is crucial in order to identify and retrieve the needed information.

\begin{tabular}{|l|l|l|l|l|l|}
\hline Model & $\begin{array}{c}\text { IFC } \\
\text { Schema }\end{array}$ & $\begin{array}{l}\text { Georefe- } \\
\text { rencing }\end{array}$ & $\begin{array}{l}\text { IfcBuildi } \\
\text { ngEleme } \\
\text { ntProxy } \\
\text { use }\end{array}$ & $\begin{array}{l}\text { Sema } \\
\text { ntics }\end{array}$ & $\begin{array}{l}\text { IFC } \\
\text { mod } \\
\text { ellin } \\
\text { g }\end{array}$ \\
\hline $\begin{array}{l}\text { Tun- } \\
\text { nel }\end{array}$ & IFC2X3 & $\begin{array}{l}\text { Yes - } \\
\text { Attribute } \\
\text { IfcPostalA } \\
\text { ddress } \\
\text { referenced } \\
\text { within } \\
\text { IfcBuildin } \\
g\end{array}$ & $\begin{array}{l}\text { Yes - } \\
\text { all the } \\
\text { infrastruct } \\
\text { ure - } \\
\text { related } \\
\text { informatio } \\
\text { n is } \\
\text { modelled } \\
\text { within thi } \\
\text { class }\end{array}$ & $\begin{array}{l}\text { Yes - } \\
\text { custo } \\
\text { m } \\
\text { proper } \\
\text { ty } \\
\text { sets }\end{array}$ & $\begin{array}{l}\text { all } \\
\text { infor } \\
\text { matio } \\
\text { n is } \\
\text { mode } \\
\text { lled } \\
\text { in 1 } \\
\text { elem } \\
\text { ent }\end{array}$ \\
\hline Bridge & IFC2X3 & $\begin{array}{l}\text { Yes - } \\
\text { Attributes } \\
\text { RefLatitud } \\
e, \\
\text { RefLongit } \\
\text { ude } \text { and } \\
\text { RefElevati } \\
\text { on within } \\
\text { IfcSite }\end{array}$ & $\begin{array}{l}\text { Yes - } \\
\text { all the } \\
\text { infrastruct } \\
\text { ure - } \\
\text { related } \\
\text { informatio } \\
\text { n is } \\
\text { modelled } \\
\text { within thi } \\
\text { class }\end{array}$ & $\begin{array}{l}\text { Yes - } \\
\text { custo } \\
\text { m } \\
\text { proper } \\
\text { ty } \\
\text { sets }\end{array}$ & $\begin{array}{l}\text { all } \\
\text { infor } \\
\text { matio } \\
\text { is } \\
\text { mode } \\
\text { lled } \\
\text { in } \\
\text { LoD1 }\end{array}$ \\
\end{tabular}

Table 1. Results from IFC inspection

It is observed that, the 'IfcBuildingElementProxy' was used to store information from various entities (which is not considered an improper approach), however it leads to a high level of abstraction, which does not facilitate the automatic interpretation of the models for other use cases. As there are not currently dedicated classes or attributes for infrastructure assets' characteristics, it is considered that modellers, apart from the spatial structures, use a lot the 'IfcBuildingElementProxy' to store both geometrical and semantic information that cannot be modelled in any other elements. For instance, at the Tunnel IFC, all the information was stored only at the 'IfcBuildingElementProxy'; there are no other classes included in the BIM model.

Similarly, there is a group of property sets in both models, containing information about the infrastructure object, as well as information about the status/ phasing of the object, which is crucial information for the SDL. To make it more general, each model is further enriched with custom property sets which contain information with regards to the stages of the design, materials used, structural information as well as geometric characteristics. This information is produced to serve the requirements during design and construction and are embedded within the IFCs as custom property sets. However, due to lack of standardization and expertise in this domain, the BIM/ IFC folders differentiate much the one from the other and it is not an easy task to identify the modelling choices of the designer/ architect. 


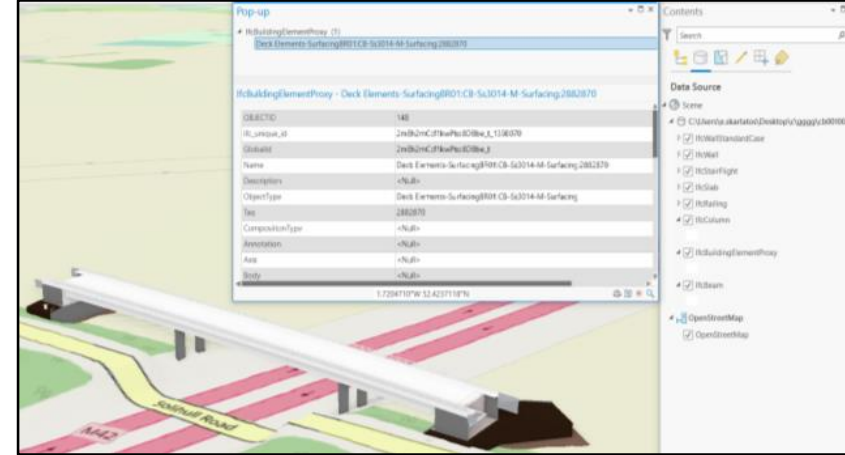

Figure 7. Information about the deck of the bridge model, modelled at the 'LA_LegalSpceInfrastructure' class.

Given this background, the mapping of the findings of this inspection are mapped to the LADM concept, to be therefore translated into classes/ attributes (Figure 8).

The lack of coverage for Infrastructure elements, in combination with the different modelling techniques as specified across different infrastructure projects demonstrate the loss of information that is taking place from the early stages of Design within the technical lifecycle. This is where the introduction of bespoke property sets is essential to address the generalisation and mis mapping of information, whilst the use of classification systems scan further contribute to standardisation of information.

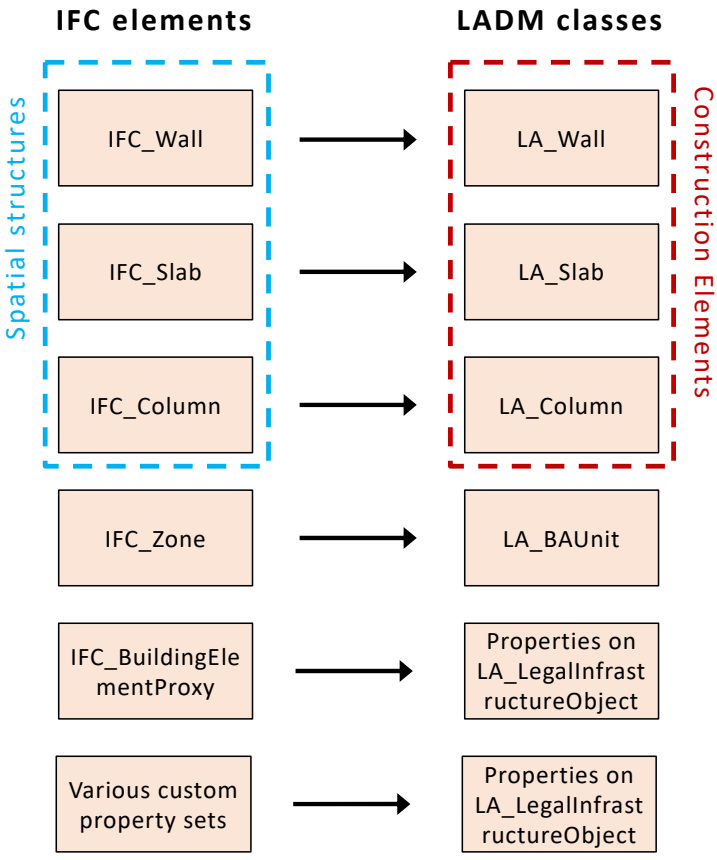

Figure 8. Mapping of IFC elements of transport infrastructure objects to the LADM concept.

It is noted that the models present similar construction objects with those used on IFC for buildings and utilise the same IFC classes with buildings (IFC Wall, IFC_Slab and ifc_Column). It was therefore considered that for the modelling of the UML diagrams, a similar modelling approach with the one proposed by Alattas et al. (2021) shall be followed. Hence, as presented in Figure 9, a new abstract class LA_ConstructionElement is proposed, which has a composition association with LA_SpatialUnit, with three subclasses: LA_Wall, LA_Slub and LA_Column.

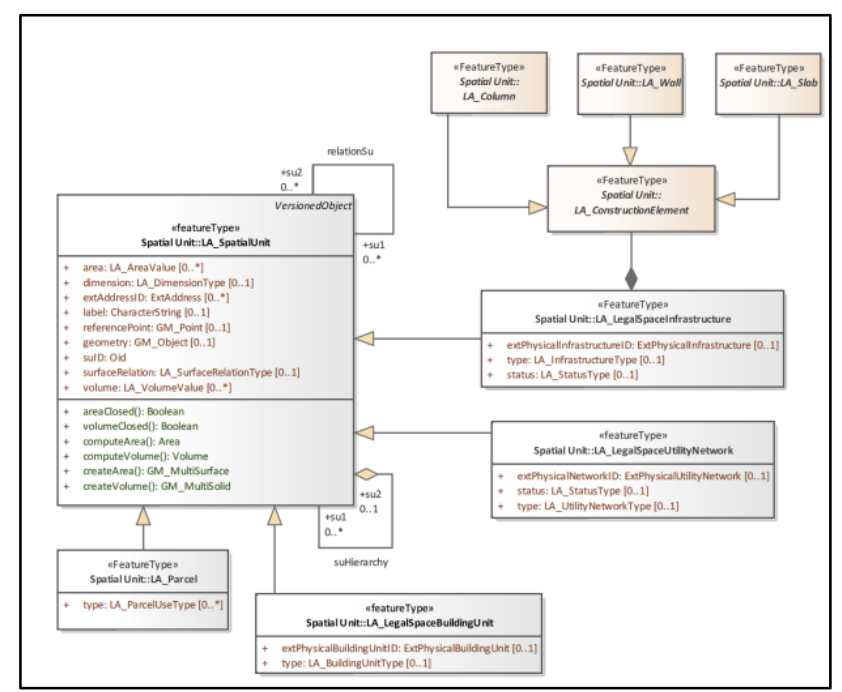

Figure 9. Proposed 'LA_LegalSpaceInfrastructure' class supporting IFC for infrastructure.

What is more, the attributes that are considered necessary for reuse in other phases of the SDL, will be modelled as attributes at the 'LA_LegalSpaceInfrastructure' class, i.e., the status of the objects, which has been already proposed as an attribute by Lemmen et al. (2021). Considering that only two IFC files have been examined to provide the modelling requirements, it is considered wise that given the initial stage of this research and the number of IFC files inspected, there are no other attributes being proposed for the 'LA_LegalSpaceInfrastructure' class.

What is more, at the IFC file of the tunnel, much information about the author/ designer is provided. This can be modelled at a conceptual level at the proposed by LADM II - Part 2 within the class 'LA_SurveyParty', that supports various roles.

\section{CONCLUSIONS \& DISCUSSION}

This paper aims to initiate the discussion on the registration of infrastructure objects in the context of ISO 19152:2012 Land Administration Domain Model (LADM) revision. Attention is given on specific categories of transport infrastructure objects by identifying the required information that can be reused from $\mathrm{BIM} / \mathrm{IFC}$ files. Given the ongoing revision of the LADM, it is well-timed to investigate the modelling of infrastructure objects that could be included in LAS and provide significant benefits, such as protecting infrastructure assets, decreasing the risk of damages and improve their management.

To articulate the requirements of infrastructure objects' data reuse and validate the proposed approach, two real world BIM files data from large-scale transport infrastructure objects are inspected against selected criteria. From the research carried out it is derived that, there are some tools to automatically validate IFC against several aspects, however, besides checking the data types/values, the presence, and the number of IFC classes being used, the rest of the data inspection process needs to be carried out manually.

From the findings, it is concluded that, at the moment, there is no structured way to model infrastructure assets through IFC, given the fact that IFC initially was not designed to store information 
of transport infrastructure and IFC Infra extension is currently under development. Therefore, storing infra-related information of IFC depends on the type of the object and modeller decision. Therefore, information (semantic and geometric) shall be stored by means of the most appropriate IFC element/ class, allowing the identification and retrieval in an automatic way. Both models contain custom property sets, which describe information that is essential for the maturity of the model stored either in the 'IfcBuildingElementProxy' class or at custom-made user Property Set, while it seems that there are times that the information exists, but it has been assigned. While various PSets fit to design and construction, they can be used to provide extra semantic information for the model. Based on those findings, an LADM-compliant model is created and visualised through a UML diagram, by enriching the 'LA_LegalSpaceInfrastructure' class.

Given the fact that BIM/ IFC models will become rapidly available across Europe and internationally, in the next few years, it is proposed to ensure a structured data flow to reuse information from previous phases of SDL. Therefore, future work of this initial research includes among others:

- the collection of more transport infrastructure assets and their inspection against the mentioned aspects and even more to enrich the findings of the study;

- the enrichment of the 'LA_LegalSpaceInfrastructure' class with more attributes and respective code list where needed;

- the enrichment of the 'LA_SurveyParty', to support party roles related to infrastructure;

- the consideration of the IFC 'spatial zone' concept during the revision of the conceptual modelling to be mapped with the LADM 'LA_BAUnit' class. To achieve it, more IFC models for the transport infrastructure shall be collected and investigated also in terms of the usage of 'IFC_Zone' element. However, in case the concept of spatial zones is not being used, it will be considered as an option to group physical elements of the assets.

- the spatial representation of transport infrastructure objects' legal spaces in combination with the 3D models of the corresponding physical spaces. This also implies to provide feedback at the survey model to be included in Part 2 of LADM Edition II for the representation of the legal boundaries of such objects. To provide a better understanding of how legal spaces of the infrastructure assets are spatially related to the private and public land parcels that they pass through, the representation of the legal boundaries of those parcels is needed.

The future steps shall consider the new concepts introduced through IFC 4.3 concerning bridge and road geometry and furniture.

\section{ACKNOWLEDGEMENTS}

The authors would like to acknowledge the contribution of Skanska UK, Highways England, HS2 and "Skanska - Costain STRABAG" Joint Venture for the data provision and industry expertise to support this research.

\section{REFERENCES}

Atazadeh, B., Rajabifard, A., Zhang, Y., Barzegar, M., 2019. Querying 3D Cadastral Information from BIM Models. ISPRS Int. J. Geo-Inf. 2019, 8, 329. doi.org/10.3390/ijgi8080329

buildingSMART Finland, 2012. Common BIM Requirements (COBIM) 2012 v1.0. Helsinki, Finland, buildingSMART Finland.
buildingSMART, 2021. Industry Foundation Classes (IFC). https://www.buildingsmart.org/standards/bsistandards/industryfoundation-classes/ (20 May 2021).

Çekin, Erhan \& Seyis, Senem. (2020). BIM Execution Plan based on BS EN ISO 19650-1 and BS EN ISO 19650-2 Standards.

Cheng, J.C.P., Lu, Q., Deng, Y., 2016. Analytical review and evaluation of civil information modeling, Autom. Constr. 67 3147. doi.org/10.1016/j.autcon.2016.02.006.

Clemen, C., Görne, H., 2019. Level of Georeferencing (LoGeoRef) using IFC for BIM. J. Geod. 2019, 10, 15-20.

Cheng, J.C.P. , Q. Lu, Y. Deng, Analytical review and evaluation of civil information modelling, Autom. Constr. 67 (2016) 31-47, dx.doi.org/10.1016/j.autcon

Clemen, C., Görne, H., (2019. Level of Georeferencing (LoGeoRef) using IFC for BIM. J. Geod. 2019, 10, 15-20.

EC, 2021. European Commission. European Construction Sector Observatory. Digitalisation in the construction sector. Analytical Report

Floros, G., Ruff, P. \& Ellul, C. 2020. Impact of Information Management during Design \& Construction on downstream BIM-GIS Interoperability for Rail Infrastructure. In ISPRS Ann Photogramm, Remote Sens. Spatial Inf. Sci., VI-4/W1-2020. 10.5194/isprs-annals-VI-4-W1-2020-61-2020.

Floros, G., Boyes, G., Owens, D. \& Ellul, C. 2019. Developing ifc for infrastructure: a case study of three highway entities. In ISPRS Ann Photogramm, Remote Sens. Spatial Inf. Sci., IV4/W8. 59-66. 10.5194/isprs-annals-IV-4-W8-59-2019.

Gelder, J. 2015. The principles of a classification system for BIM: Uniclass 2015. In 49th International Conference of the Architectural Science Association, 2015, pp.287-297.

Ghang, Lee, André, Borrmann, (2020) BIM policy and management, Construction Management and Economics, 38:5, 413-419, doi: 10.1080/01446193.2020.1726979

INSPIRE, 2009. INSPIRE Thematic Working Group Transport Networks.

Kalogianni, E., van Oosterom, P., Dimopoulou, E., Lemmen, C., 2020. 3D Land Administration: A Review and a Future Vision in the Context of the Spatial Development Lifecycle. ISPRS Int. J. Geo-Inf. 2020, 9, 107. doi.org/10.3390/ijgi9020107.

Kumar, K., Labetski, A., Ohori, K.A., Ledoux, H., Stoter, J. 2019, Harmonising the OGC Standards for the Built Environment: A CityGML Extension for LandInfra. ISPRS Int. J. Geo-Inf. 2019, 8, 246. doi:10.3390/ijgi8060246.

Kurwi, S., Demian, P., Blay, K.B., Hassan, T.M., 2021. Collaboration through Integrated BIM and GIS for the Design Process in Rail Projects: Formalising the Requirements. $\begin{array}{llll}\text { Infrastructures } & 2021, & 62 & \end{array}$ doi.org/10.3390/infrastructures6040052.

Kutzner, T., Chaturvedi, K., Kolbe, T.H., 2020. CityGML 3.0: New Functions Open Up New Applications. PFG 88, 43-61 doi.org/10.1007/s41064-020-00095-z. 
Lemmen, C., Alattas, A., Indrajit, A., Kalogianni, E., Kara, A., Oukes, P., van Oosterom, P, 2021. The Foundation of Edition II of the Land Administration Domain Model. FIG WW2021

Liu, X., Wang, X., Wright, G., Cheng, J., Li, X., Liu, R., 2017. A state-of-the-art review on the integration of Building Information Modeling (BIM) and Geographic Information System (GIS). ISPRS Int. J. Geo-Inf. 2017, 6, 53.

NBS, 2021. Uniclass 2015 https://www.thenbs.com/ourtools/uniclass-2015. (20 May 2021).

OGC (2016). OGC®Land and Infrastructure conceptual model standard. Document No. 15-111r1; 2016.

OGC (2019). OGC® Model for Underground Data Definition and Integration (MUDDI) Engineering Report.

Oxford University Press, 2016. Definition of infrastructure, Oxford University Press, 2016.

Rajabifard, A., Atazadeh, B., Kalantari, M., 2019. BIM and Urban Land Administration, CRC Press.

Rijksgebouwendients, 2013. Rgd BIM Standard. Rijksgebouwendients, The Netherlands.

Statsbygg (2020). Statsbygg BIM Manual. Available at: http://www.eubim.eu/wp- content/uploads/2019/08/2019-0828_EU_BIM_Task_Group_Statsbygg_BIM_Manual_20_v101. pdf.

Strange I., 2018 Urban Planning and City Futures: Planning for Cities in the Twenty-First Century. In Dastbaz M., Naudé W., Manoochehri J. (eds) Smart Futures, Challenges of Urbanisation, and Social Sustainability. Springer, Cham.

Theiler, M. and Smarsly, K. 2018. IFC Monitor - An IFC schema extension for modeling structural health monitoring systems. In Advanced Engineering Informatics 37, .45-56. https://doi.org/10.1016/j.aei.2018.04.011. 